\title{
Long-term Follow-up of Optic Disc Pit Maculopathy Treated with Laser Photocoagulation: A Case Report
}

\author{
Sergios Taliantzis, (1) Asli Perente, (1) Christina Mitsi, (1) Eirini Kanella Panagiotopoulou, \\ iD loannıs Fotiadis, (iD Doukas Dardabounis \\ Department of Opthalmology, University Hospital of Alexandroupolis, Alexandroupolis, Greece
}

\begin{abstract}
This report describes a case of optic disc pit maculopathy treated successfully with laser photocoagulation. Optical coherence tomography (OCT) was used to assess the optic nerve and the macular area. Green laser photocoagulation was performed in an arcuate pattern to manage the macular edema. Eighteen months later, OCT showed complete regression of the macular edema. Fifty months after the laser treatment, visual acuity remained 20/20. The results of an Amsler grid test were negative and the macular area was visualized as normal. Slit-lamp laser photocoagulation is a minimally invasive technique that should be considered as a first-line treatment option in patients with optic pit maculopathy who retain their visual capacity.
\end{abstract}

Keywords: Green laser, metamorphopsia, minimal invasive treatment, optical coherence tomography, optic disc pit.

\section{Introduction}

Optic disc pit (ODP) is a rare, congenital anomaly with an incidence of $\mathrm{I}$ in II.000 individuals that typically appears as a circumscribed, discolored (often gray), oval-shaped depression of the optic disc (I). It is thought to arise due to an incomplete closure of the fetal fissures affecting the lamina cribrosa; a herniation of dysplastic retinal tissue becomes a collagen-rich excavation extending toward the subarachnoid space (2). Most cases are asymptomatic, though significant visual deterioration may be observed when maculopathy occurs, a complication detected in $25 \%$ to $75 \%$ of patients with ODP (3). ODP maculopathy (ODP-M) is a clinical entity, which presents with serous detachment, cystic degeneration, and changes to the retinal pigment epithelium, and is characterized by the accumulation of intraretinal and/or subretinal fluid (3).

Several theories have been proposed to explain the origin of the fluid seen in ODP-M. Possibilities reported include the vitreous body, the choroid, cerebrospinal fluid, and leakage from blood vessels at the site of the ODP (I).

There are no universally accepted guidelines for the treatment of ODP-M; however, laser photocoagulation, vitrectomy, gas tamponade and/or inner limiting membrane (ILM) peeling, macular buckling surgery, and recently, autologous platelet injection after pars plana vitrectomy, are among the

How to cite this article: Taliantzis S, Perente A, Mitsi C, Panagiotopoulou EK, Fotiadis I, Dardabounis D. Long-term Follow-up of Optic Disc Pit Maculopathy Treated with Laser Photocoagulation: A Case Report. Beyoglu Eye J 202 I; 6(2): I5I-154.

Address for correspondence: Asli Perente, MD. Alexandroupolis Universite Hastanesi, Goz Hastaliklari Bolumu, Alexandroupolis, Yunanistan Phone: +306951577205 E-mail: asli_perende-90@hotmail.com

Submitted Date: January 02, 2021 Accepted Date: March 14, 2021 Available Online Date: June 08, 2021

${ }^{\odot}$ Copyright 2021 by Beyoglu Eye Training and Research Hospital - Available online at www.beyoglueye.com OPEN ACCESS This work is licensed under a Creative Commons Attribution-NonCommercial 4.0 International License. 
therapeutic interventions used in clinical practice (4).

This case of ODP-M was successfully managed with laser photocoagulation.

\section{Case Report}

A 66-year-old male patient presented at the outpatient service complaining of blurred vision in his right eye. A full ophthalmological examination was performed. His uncorrected visual acuity (UVA) was 20/20 in both eyes, but the results of an Amsler grid test were positive in the right eye. The intraocular pressure (IOP) was $35 \mathrm{mmHg}$ in the right eye (OD) and $15 \mathrm{mmHg}$ in the left eye (OS). No abnormalities were observed in the anterior segment. A dilated fundus examination disclosed a glaucomatous optic disc with an estimated cup to disc ratio of 0.8 and retinal elevation from the optic disc to the foveola in the OD. Optical coherence tomography (OCT) revealed an optic pit with serous detachment of the retina in the OD. Treatment with a prostaglandin analogue to be administered in a dose of one drop once daily was introduced and a 6-month follow-up program was suggested. On re-examination 6 months later, the UVA was found to be unchanged and the IOP in the OD was $13 \mathrm{mmHg}$. However, the patient mentioned a significant worsening of the metamorphopsia symptoms that affected his daily life activities. OCT showed a progression of intraretinal fluid toward the foveola. To address the deterioration of the clinical picture, 14 burns with a green laser were performed in an arcuate pattern $(60-27 \mathrm{~mW}$ of energy and spot size of $50 \mu \mathrm{m})$ (Fig. I) at the temporal side
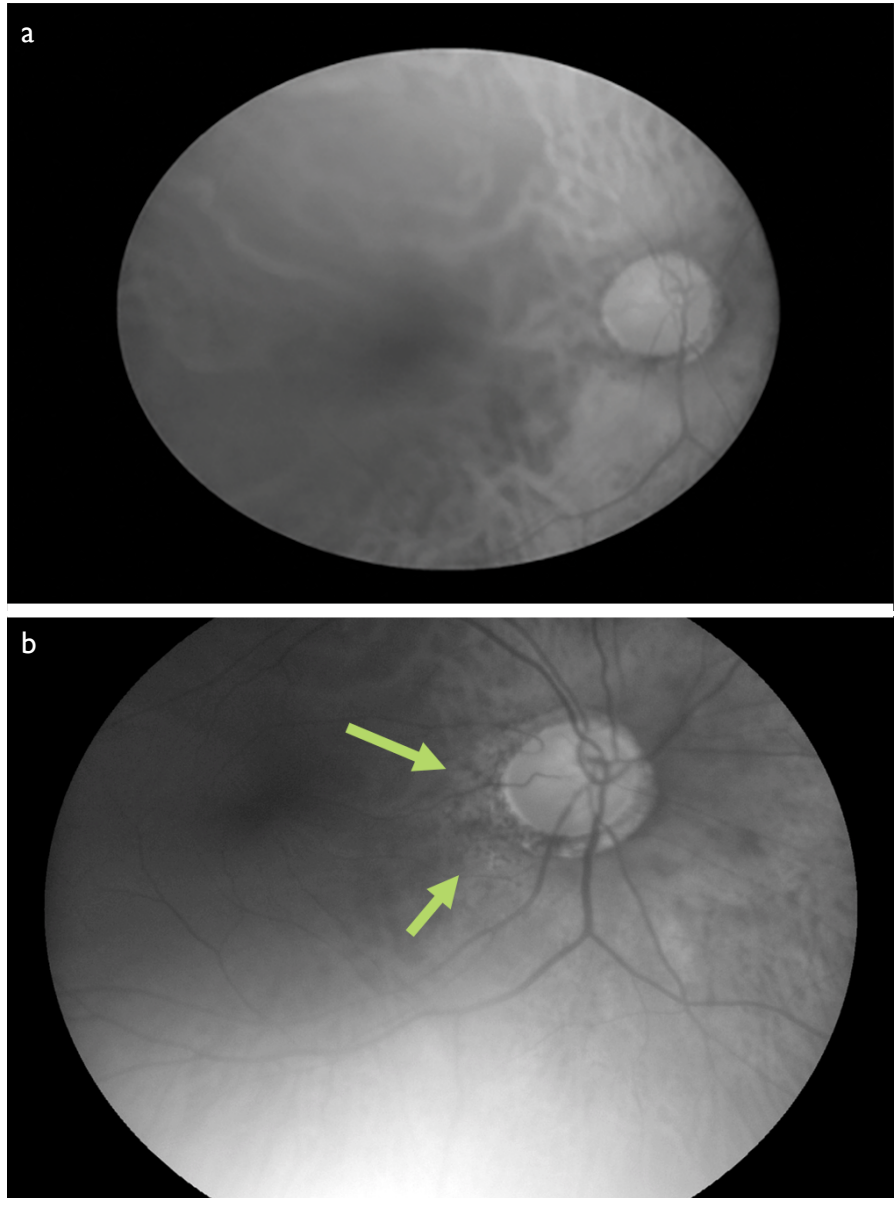

Figure 2. (a) Infrared fundus photograph of the right eye before laser photocoagulation. (b) Infrared fundus photograph of the right eye after laser photocoagulation showing the laser scars on the temporal side of the optic disc (green arrows).
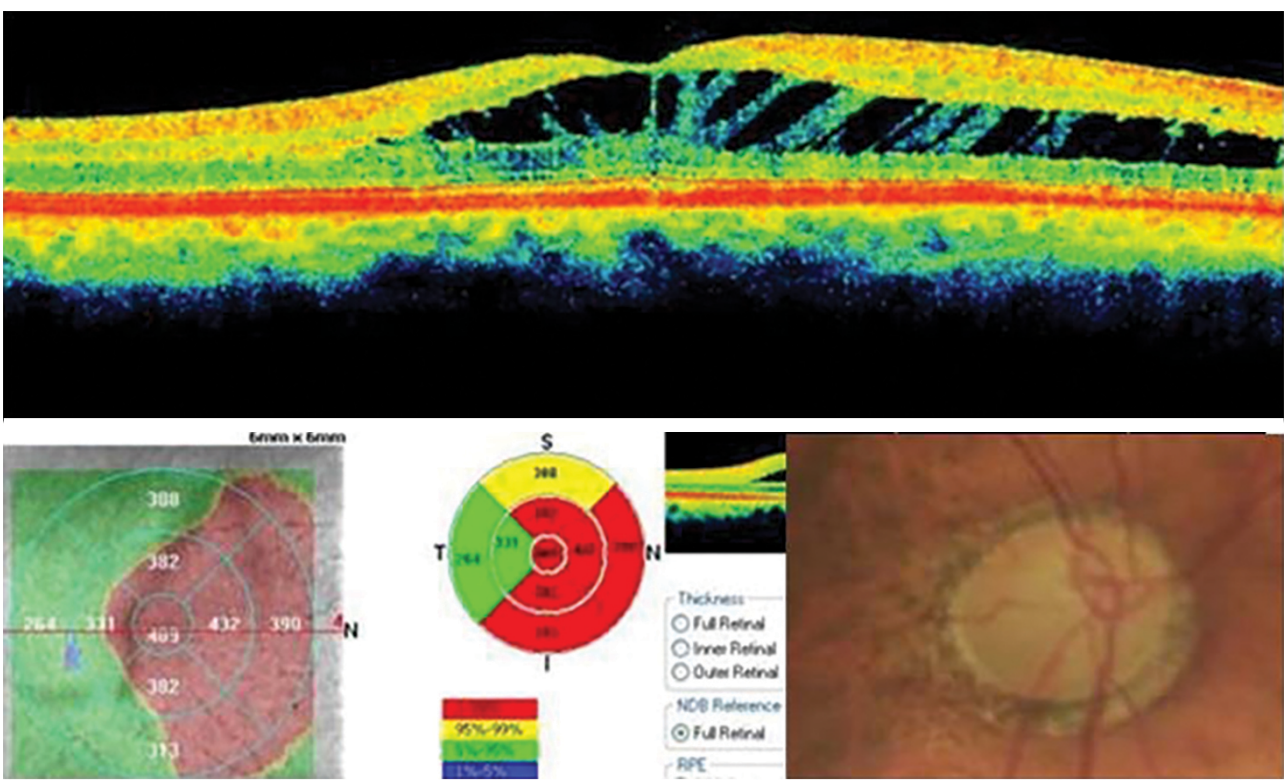

Figure I. Optical coherence tomography images of the right eye showing fluid in the outer nuclear layer of the retina and a color fundus photograph of the right optic disc indicating the presence of an optic disc pit. 
of the right optic disc (Fig. 2). Eight months later, it was observed that the macular edema had improved, and 18 months after the treatment, no fluid was detected on OCT. Fifty months after the laser treatment, the UVA remained $20 / 20$, an Amsler test was negative, there were no subjective complaints of metamorphopsia, the IOP was normal, and complete regression of the macular edema was visible on OCT (Fig. 3).

\section{Discussion}

ODP is one of several congenital cavitary anomalies with a similar impact on visual capacity. ODP is characterized by isolated cavitations, usually located on the temporal side of the optic disc. Related maculopathy occurs in 2 steps: intraretinal pooling of fluid and consequent retinoschisis, and extension of the fluid in the subretinal layers through an outer break $(3,5)$.

Although spontaneous resolution has been reported in approximately $25 \%$ of cases, the general visual prognosis is poor. Steel et al. (6) conducted a retrospective study of 134 eyes to evaluate the risk factors associated with poor vision in patients with ODP-M. The researchers found that extension of the edema beyond the vascular arcades and the presence of both subretinal fluid and outer retinal layer fluid were among the primary determinants for poor visual acuity.

Different treatment options for ODP-M have been proposed; however, the efficacy of each therapeutic intervention seems to be controversial. Pars plana vitrectomy with laser treatment, gas tamponade, and/or ILM peeling is the most used surgical procedure, with a reported success rate of approximately 50\% (5). Pneumatic retinopexy with an intravitreal gas tamponade with or without laser application is another therapeutic option with encouraging outcomes (7). Scleral buckling is a newer surgical approach with satisfactory long-term visual and anatomical outcomes proposed by Theodossiadis et al. (8).

Slit-lamp laser photocoagulation is an initial, minimally invasive treatment options for the management of ODP-M. Laser spots applied to the temporal side of the peripapillary area are used to create chorioretinal adhesion, which interrupts circulation of the fluid into the subretinal space (9).

According to the available literature data, the efficacy of laser treatment is controversial; some published reports demonstrate full absorption of fluid and reattachment of the retina after laser photocoagulation, while other reports note low success rates and severe perimetrical defects (9).

In our case, the macular edema completely resolved following laser treatment, and the disturbing metamorphopsia was eliminated. The patient's visual capacity remained consistent for the follow-up period of 50 months, with no signs of macular edema. Inferotemporally, there was a significant retinal nerve fiber layer (RNFL) loss detected during follow-up. However, temporally, there was no loss of RNFL seen where laser photocoagulation was applied. The inferotemporal RNFL loss may have been a result of advanced glaucoma (Fig. 4). In conclusion, given that slit-lamp laser photocoagulation is a minimally invasive technique, it should be considered as a first-line option, particularly in patients who have maintained their visual acuity despite macular edema.

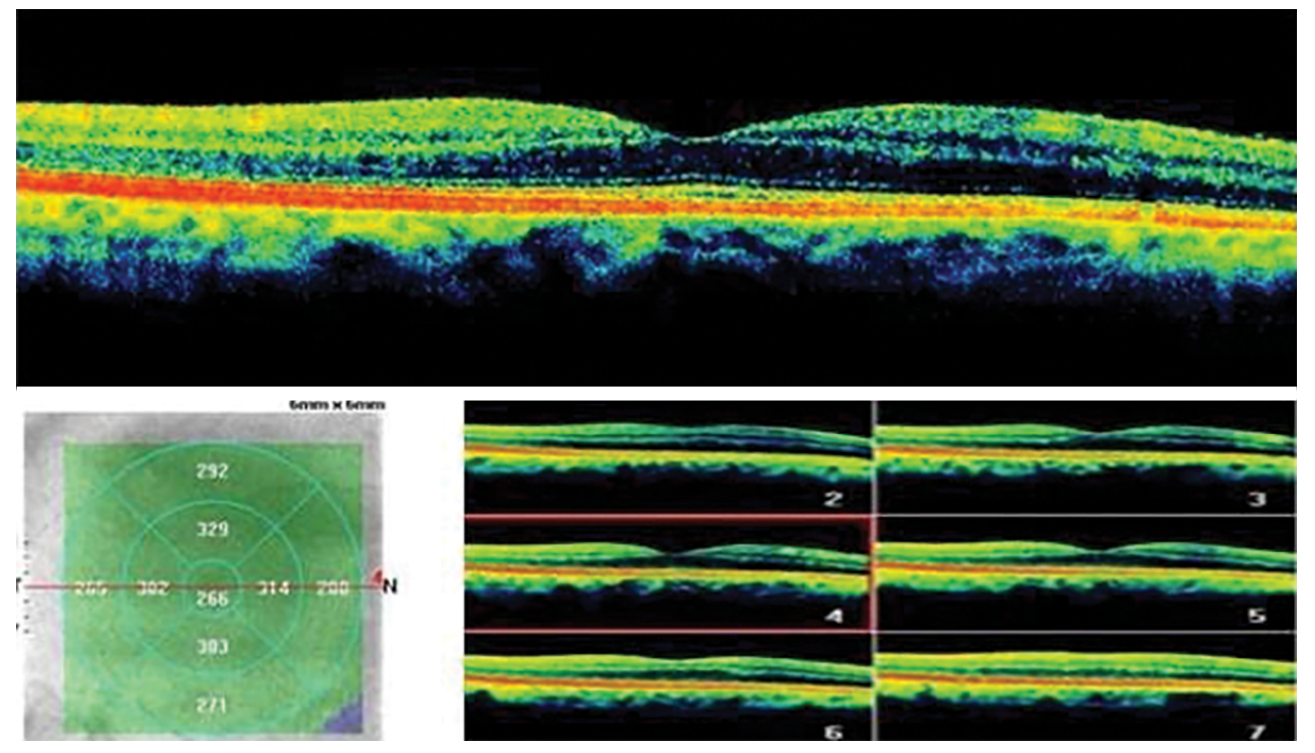

Figure 3. Optical coherence tomography images of the right eye 50 months after the laser photocoagulation treatment. 
Nerve Fiber ONH/GCC Change Analysis

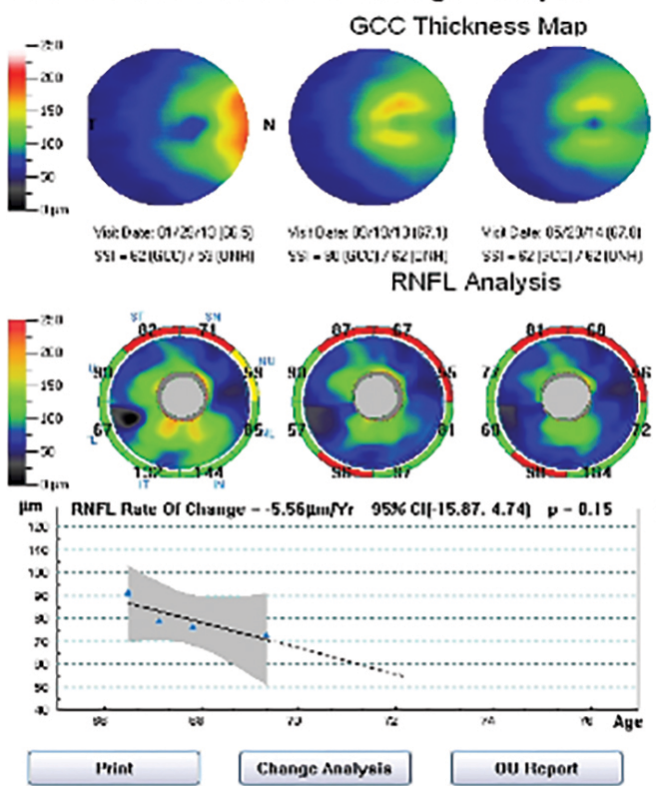

Right / OD
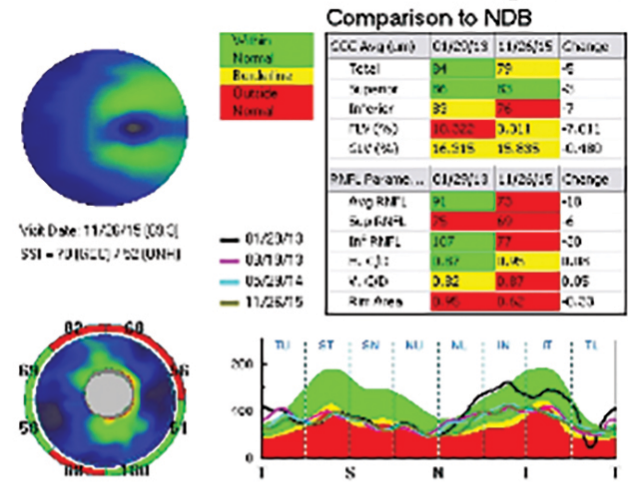

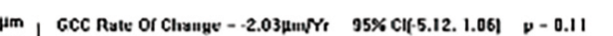

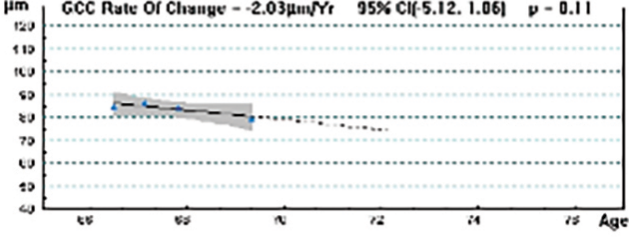

optovve

Figure 4. Nerve fiber optic nerve head/ganglion cell complex analysis of the right eye.

GCC: Ganglion cell complex; NDB: Normative database; RNFL: Retinal nerve fiber layer

\section{Disclosures}

Informed consent: Written informed consent was obtained from the patient for the publication of the case report and the accompanying images.

Peer-review: Externally peer-reviewed.

Conflict of Interest: None declared.

Authorship Contributions: Involved in design and conduct of the study (ST); preparation and review of the study (DD, IP, AP, CM, EKP); data collection (EKP, CM, AP).

\section{References}

I. Moisseiev E, Moisseiev J, Loewenstein A. Optic disc pit maculopathy: when and how to treat? A review of the pathogenesis and treatment options. Int J Retina Vitreous 20I5; I: I3. [CrossRef]

2. Ferry AP. Macular detachment associated with congenital pit of the optic nerve head. Pathologic findings in two cases simulating malignant melanoma of the choroid. Arch ophthalmol 1963;70:346-57. [CrossRef]

3. Georgalas I, Ladas I, Georgopoulos G, Petrou P. Optic disc pit: a review. Graefes Arch Clin Exp Ophthalmol 201 I;249: I I I3-22.
4. Shah SD, Yee KK, Fortun JA, Albini T. Optic disc pit maculopathy: a review and update on imaging and treatment. Int Ophthalmol Clin 2014;54:6I-78. [CrossRef]

5. Chatziralli I, Theodossiadis P, Theodossiadis GP. Optic disk pit maculopathy: current management strategies. Clin Ophthalmol 2018; I2:14|7-22. [CrossRef]

6. Steel DH, Williamson TH, Laidlaw DA, Sharma P, Matthews C, Rees J, et al. Extent and location of intraretinal and subretinal fluid as prognostic factors for the outcome of patients with optic disk pit maculopathy. Retina 2016;36:1 10-8. [CrossRef]

7. Wan R, Chang A. Optic disc pit maculopathy: a review of diagnosis and treatment. Clin Exp Optom 2020;103:425-9. [CrossRef]

8. Theodossiadis GP, Chatziralli IP, Theodossiadis PG. Macular buckling in optic disc pit maculopathy in association with the origin of macular elevation: 13-year mean postoperative results. Eur J Ophthalmol 20I5;25:24I-8. [CrossRef]

9. Kalogeropoulos D, Ch'ng SW, Lee R, Elaraoud I, Purohit M, Felicida V, et al. Optic Disc Pit Maculopathy: A Review. Asia Pac J Ophthalmol (Phila) 2019;8:247-55. 